\title{
O primeiro ano em revisão do novo ciclo da medicina geral e familiar: mudanças e perspetivas
}

Alberto Hespanhol,* Tiago Maricoto,* Paulo Santos,* Rui Nogueira*

A

Revista Portuguesa de Medicina Geral e FaMILIAR, anteriormente designada de REVISTA Portuguesa de Clínica Geral, iniciou a sua atividade em 1984, assumindo-se desde logo como o órgão de referência da publicação científica em Portugal da nossa especialidade. Desde então a revista passou pelas mãos de diversas equipas editoriais, cada uma contribuindo de forma inabalável e incomparável para o seu crescimento, consolidação e afirmação.

A especialidade da Medicina Geral e Familiar não ficou indiferente ao salto científico da medicina moderna e reorganizou a sua estrutura, âmbito e missão, para agora se afirmar como a referência do Serviço Nacional de Saúde em cuidados prestados à população. Esta rápida e avassaladora evolução traz novos desafios e o método científico é hoje não só a ferramenta de trabalho dos clínicos, mas também das organizações e sistemas em si, que se revolucionaram em novos modelos de trabalho e de estrutura. A Revista Portuguesa DE Medicina Geral e FAMiLIar pode assumir um papel fundamental nesta revolução e assim foi assumido pelo atual corpo editorial aquando do início das suas funções, que seria este o seu âmbito primordial. ${ }^{1-4}$ Muitas mudanças foram já introduzidas, com o objetivo de dar maior grandeza, rigor e agilidade à revista. $\mathrm{O}$ trajeto é longo e moroso, mas a muitos contributos se devem os grandes passos que foram já alcançados. Entre diferentes tarefas e mudanças implementadas durante este último ano destacam-se algumas que são importantes do ponto de vista estratégico, a saber:

- Foi feita uma reestruturação administrativa e funcional, desenvolvendo e reforçando o corpo editorial e otimizando o processo editorial;

- Atualizaram-se as normas de publicação, adaptando-as à atualidade e à vanguarda da publicação científica;

*Conselho editorial da Revista Portuguesa de Medicina Geral e Familiar
- Renovou-se o conselho científico da revista, uma peça basilar, capital e garantia da idoneidade, rigor e creditação. Contamos com a sua intervenção e opinião crítica, bem como apoio científico em áreas pertinentes da medicina geral e familiar;

- Criou-se uma nova equipa editorial, mais alargada, e com o novo conceito de inclusão regular de editores juniores em processo de formação;

- Alargou-se o plano de indexação para maior visibilidade e impacto, nomeadamente às bases da Crossref, que motivou ainda a inclusão de DOI em todos os números e artigos, da Directory of Research Journals Indexing, da Index Copernicus e da EBSCO;

- Transitou-se para a era digital, com a publicação em versão digital exclusiva;

- Iniciou-se a publicação dos resumos dos principais e mais credenciados eventos científicos da Associação Portuguesa de Medicina Geral e Familiar;

- Alargou-se a equipa de revisores e com isso conquistou-se uma significativa redução do tempo médio de revisão, um investimento precioso para o futuro da revista.

O processo editorial é difícil e moroso, os artigos necessitam de uma cuidada análise na revisão por pares e a garantia da ocultação e da qualidade obriga muitas vezes a várias rondas de maturação até à publicação. Este é e será sempre um primado na revista. E, de facto, um dos grandes desafios que esta nova equipa enfrentou foi o longo tempo de revisão e de publicação. Em relação ao primeiro, a redução foi significativa, desde uma média de cerca de um ano, para os atuais cerca de quatro meses de tempo médio de revisão. Em relação ao segundo, o mesmo ainda não se verifica, pois o tempo até publicação ainda é de cerca de um ano, mas o desafio continua e o objetivo mantém-se inabalável para o próximo ciclo.

Isto é fruto do grande número de artigos submetidos 
nos últimos anos. A revista recebe quase duzentos artigos por ano para serem publicados, o que lança um grande desafio para o próximo ciclo, obrigando a uma otimização constante do processo editorial. Com uma taxa de aceitação de cerca de $60 \%$, a revista publica mais de 60 artigos por ano e muitos de elevada qualidade ficam excluídos, pela inerência da nossa capacidade.

Não obstante, o rigor deverá ser maior, a qualidade mais aprimorada e a originalidade permanente, de forma a ambicionar voos mais altos, com mais visibilidade, com mais impacto, com uma maior e melhor indexação.

Findo este primeiro ciclo, o corpo editorial endereça os mais sinceros agradecimentos a todos os colaboradores que nos permitiram dar estes grandes passos, desde os leitores, aos autores, aos revisores, aos editores, à equipa administrativa e de secretariado e até todos aqueles que em algum momento fizeram e fazem a diferença. A revista está agora, mais do que nunca, preparada para entrar na linha da frente e espera contar com a colaboração de todos nós, pois todos estamos convocados para fazer parte do próximo ciclo.

\section{REFERÊNCIAS BIBLIOGRÁFICAS}

1. Nogueira R.A partilha do conhecimento num novo ciclo [Sharing knowledge in a new cycle]. Rev Port Med Geral Fam. 2017;33(3):170. Portuguese

2. Hespanhol AP. Um ponto de situação do novo modelo editorial da revista [The current situation of the new editorial model of the RPMGF]. Rev Port Med Geral Fam. 2017;33(5):310-2. Portuguese

3. Hespanhol AP. Contributo de novo modelo editorial da revista para a formação e a investigação em medicina geral e familiar [Contribution of a new editorial model for continuous education and research in general and family medicine]. Rev Port Med Geral Fam. 2017;33(4):242. Portuguese

4. Santos P, Maricoto T, Hespanhol A, Nogueira R. O novo ciclo da medicina geral e familiar [The new cycle of general family medicine]. Rev Port Med Geral Fam. 2018;34(3):123. Portuguese

\section{ENDEREÇO PARA CORRESPONDÊNCIA}

E-mail: tiago.maricoto@gmail.com

https://orcid.org/0000-0002-4201-9565 